\title{
Status epilepticus: Using antioxidant agents as alternative therapies (Review)
}

\author{
LILIANA CARMONA-APARICIO $^{1 *}$, CECILIA ZAVALA-TECUAPETLA ${ }^{2 *}$, MARÍA EVA GONZÁLEZ-TRUJANO ${ }^{3}$, \\ ARISTIDES III SAMPIERI ${ }^{4}$, HORTENCIA MONTESINOS-CORREA ${ }^{5}$, LETICIA GRANADOS-ROJAS ${ }^{1}$, \\ ESAÚ FLORIANO-SÁNCHEZ ${ }^{6}$, ELVIA COBALLASE-URRUTÍA ${ }^{1}$ and NOEMÍ CÁRDENAS-RODRÍGUEZ ${ }^{1}$
}

${ }^{1}$ Laboratory of Neurosciences, National Institute of Pediatrics, Mexico City $04530 ;{ }^{2}$ Laboratory of Physiology of The Reticular Formation Reticular, National Institute of Neurology and Neurosurgery, Mexico City 14269;

${ }^{3}$ Laboratory of Neuropharmacology of Natural Products, National Institute of Psychiatry Ramón de la Fuente Muñiz, Mexico City 14370; ${ }^{4}$ Department of Comparative Biology, Faculty of Sciences, National Autonomous University of Mexico, Mexico City 04150; ${ }^{5}$ Services of Endocrinology, National Institute of Pediatrics, Mexico City 04530;

${ }^{6}$ Military School of Graduate of Health, Multidisciplinary Research Laboratory, Secretariat of National Defense, Mexico City 11270, Mexico

Received October 23, 2015; Accepted April 5, 2016

DOI: $10.3892 /$ etm.2016.3609

\begin{abstract}
The epileptic state, or status epilepticus (SE), is the most serious situation manifested by individuals with epilepsy, and SE events can lead to neuronal damage. An understanding of the molecular, biochemical and physiopathological mechanisms involved in this type of neurological disease will enable the identification of specific central targets, through which novel agents may act and be useful as SE therapies. Currently, studies have focused on the association between oxidative stress and SE, the most severe epileptic condition. A number of these studies have suggested the use of antioxidant compounds as alternative therapies or adjuvant treatments for the epileptic state.
\end{abstract}

\section{Contents}

1. Overview of status epilepticus (SE)

2. Oxidative stress in status epilepticus

3. Physiological and therapeutic relevance

Correspondence to: Dr Noemí Cárdenas-Rodríguez or Dr Elvia Coballase-Urrutía, Laboratory of Neurosciences, National Institute of Pediatrics, Av Iman 1 Insurgentes Cuicuilco, Mexico City 04530, Mexico

E-mail: noemicr2001@yahoo.com.mx

E-mail: elcoballase@yahoo.com.mx

*Contributed equally

Key words: epilepsy, oxidative stress, epileptic state, antioxidant agents

\section{Overview of status epilepticus (SE)}

Epilepsy generalities. Epilepsy is a group of different types of disorders that share an abnormally increased tendency to cause convulsive seizures (1). Epilepsy is a chronic neurological disorder characterized by abnormal organization of neuronal electrical activity leading to alterations in a neuronal population, which manifests in seizures, behavioral changes or impaired neuronal activity (1-4). The International League Against Epilepsy (ILAE) defines epilepsy as 'a pathological condition because of the presence of two or more recurrent seizures over a period longer than 24 h unprovoked' $(5,6)$. The incidence of this neurological disease is high in children, stable in adults and increases in the final decades of life (7-11).

Classification of seizures. Based on their etiology, the seizures are classified as follows: i) Idiopathic (primary), associated with heredity; ii) symptomatic (secondary), associated with damage in the brain, including trauma, tumors, bleeding, infection, vascular malformations or metabolic abnormalities; and iii) cryptogenic, seizures with an unknown cause (12-14).

Seizures are focal or generalized, depending on the location of hypersynchronic activity (13-16). Focal seizures are caused by an electrical shock in a particular region of the brain, and can spread to the entire brain. Patients with focal seizures may or may not experience loss of consciousness (simple or complex seizures, respectively) (13-17). Generalized seizures are those in which the altered electrical activity occurs in the two cerebral hemispheres concurrently $(3,9)$. In this type of seizure, a generalized motor impairment with or without autonomic disruption can occur, characterized by an electroencephalogram pattern that is bilateral, synchronous and symmetrical in the hemispheres (14-16). 
Generalities of status epilepticus (SE)

$\mathrm{SE}$ is a term used to describe a condition resulting from the failure of the mechanisms associated with seizure termination, or from the initiation of mechanisms that lead to prolonged seizures (18). According to the ILAE in 2015, a recent classification of SE has been proposed based on a clinical diagnosis, and on an investigation and therapeutic approaches for each patient (19). The following operational definition of SE has been proposed: In adults and children $>5$ years old was defined as $\geq 5$ min of continuous seizure or $\geq 2$ seizures during which there is incomplete recovery of consciousness $(19,20)$. There are 3 principal factors that determine the risk of mortality and morbidity in SE: i) Etiology of seizure (principally infection in children; trauma, metabolic disruptions or intoxication in adults); ii) age $\geq 60$ years old; and iii) duration and development of SE (the majority of patients with SE have no history of seizures, presenting a risk of development of chronic epilepsy) (21-25). Generalized convulsive SE is the most frequently observed type, however, non-convulsive SE is difficult to diagnose as it can be confused with other neurological and psychiatric disorders (26).

Etiology, initiation and propagation of SE. SE results from an alteration of the mechanisms that usually terminate a single and prolonged seizure (27). This alteration may result in constant neuronal excitation, or in failure of the inhibition mechanisms, and it has been suggested that reverberating seizure activity is induced in hippocampal structures and its progress is a sequence of distinct electrophysiological changes (28).

In temporal lobe epilepsy (TLE), an SE episode is generally considered a trigger that initiates epileptogenesis. It has been suggested that seizure initiation is produced by a dysregulation between the excitatory and inhibitory systems, leading to irregular neuronal activity (27). Furthermore, it has been suggested that protein phosphorylation, ion channel opening and closure, release of neurotransmitters and modulators and receptor desensitization occur during the first few seconds of a seizure. In addition, within seconds to minutes the movement of existing receptors to the synaptic membrane occurs. This process alters the activity of inhibitory and excitatory receptors available in the synaptic cleft (29). Furthermore, within minutes to hours, plastic changes in neuropeptide modulators occur, leading to a state of increased excitability (27).

When measured by in vivo intracerebral microdialysis, an increase in the levels of glutamate is the beginning of seizure activity in adults with TLE (30-32). The same mechanism may happen during the onset of generalized seizures. Inhibitory neurotransmitters increase in the seizure site and reestablish the balance between excitation and inhibition response (31).

Neurotoxicity and neuroprotection in SE. In SE, neuronal damage is the consequence of sustained N-methyl-D-aspartate receptor stimulation that leads to apoptosis. The cell destruction that is generated in this manner can be reversed if the SE is terminated within the first hour (27). The investigation for acute or chronic therapies should be based on the patient age, gender and genetic predisposition in addition to the $\mathrm{SE}$ etiology. In this manner, understanding the spectrum of SE may lead to the identification of neuroprotective treatments that are specific for the developing central nervous system, to diminish the consequences of SE.
Experimental models of SE. SE models are currently used to study the transition from a single SE episode to chronic epilepsy. Experimental models are used that comprise the seizure-initiating mechanisms, and that may facilitate the identification of novel therapeutic strategies for improving the treatment of SE (26). Systemic administration of pilocarpine (a muscarinic receptor agonist), systemic or local administration of kainic acid as a potent glutamate receptor agonist or protocols that electrically stimulate specific brain areas are the animal model most used for the study of SE (33-36).

Systemic or local convulsant chemicals. Systemic or intracerebral injection of pilocarpine induces seizures that originate in limbic regions. This results in structural damage and possible spontaneous recurrent seizures that resemble the etiology of human complex partial seizures, such as between human TLE and the pilocarpine model. Neurotrophins have been demonstrated to be altered in the hippocampus of patients with mesial TLE and in the hippocampus and neocortex of pilocarpine-treated rats $(37,38)$. Furthermore, cognitive and memory deficits are commonly observed in TLE patients and are also present in pilocarpine-injected rats $(26,39)$.

In addition, SE has been induced by intracerebral administration in the amygdala or hippocampal structures. Pilocarpine (intrahippocampal injection of $2.4 \mathrm{mg} / \mu \mathrm{l}$; injected volume $1.0 \mu \mathrm{l})$ induces SE and spontaneous recurrent seizures with low mortality (40).

Kainic acid was one of the first compounds used in the TLE rodent model (systemic or intracerebral administration). It induces neuronal depolarization, and often generalized seizures secondary to partial seizures, commonly begin in the hippocampus. Rodents exhibit remarkable hippocampal sclerosis as a consequence of the neurological damage induced by the seizures. Kainic acid has the advantage of causing injuries that are usually restricted to the hippocampus, in comparison with pilocarpine, which can also result in lesions in neocortical areas $(26,39)$. Lower doses of kainic acid produce low mortality and seizures rates with relatively long latent periods (40).

SE induction by electrical stimulation. Perforant path stimulation (PPS) is widely used to produce continuous seizures in rats and was established by Sloviter in 1991 (41). In this model, anesthetized rats receive discontinuous PPS for one day, which is usually caused by a bipolar stimulating electrode implanted into the angular bundle of the perforant pathway resulting in brain lesions based on the stimulated area, time and intensity of the stimulus (26). The histopathological findings are similar to the kainic acid and pilocarpine model although with less neurodegeneration.

The self-sustained limbic SE model by Lothman et al (42) is provoked by continuous and localized electrical stimulation of the hippocampus. In this model, a normalized electrical stimulus is determined by each rat and in adequate conditions (length and side of stimuli or kindling application), the SE persists for hours after ceasing the stimulus. This model induces SE without producing the excitotoxic effect observed in the kainic acid or pilocarpine models.

SE models in immature animals. Clinical studies have noted that a broad range of children have suffered an episode of convulsive SE, and that incidence varies widely globally (13-74\%). Thus, animal models of SE are important for investigating whether long-lasting seizures in the developing 
brain can result in neuronal disorganization, epileptogenesis or cognitive impairment $(22,43,44)$.

Pentylenetetrazol [a non-competitive $\gamma$-aminobutyric acid (GABA) antagonist] also leads to SE in immature animals when administered systemically at postnatal day 10 or 21 (45), similar to the models of kainic acid, lithium-pilocarpine and electrical stimulation protocols but with lower doses. In these models, seizure manifestation increases with age and induces neuronal loss in the hippocampus, amygdala and mediodorsal nucleus of the thalamus of a developing brain. However, the exact mechanisms have not been fully characterized. Nevertheless, young rats do not display the clear neuronal reorganization that is frequently observed in adults $(26,46-51)$.

Recently, Mareš et al (52) demonstrated that SE induced by pilocarpine at P12 and P25 produced cognitive damage that increased with age and is correlated with the portion of the injured brain, but not with seizure parameters.

\section{Oxidative stress in status epilepticus}

Oxidative stress in epilepsy. The study of different illnesses of the nervous system has focused on the imbalance between the oxidant and antioxidant system since $1990(53,54)$. The first experimental evidence describing an association between oxidative stress and epilepsy was presented by Armstead et al (55) in 1989. The authors demonstrated that the enzyme superoxide dismutase (SOD) was increased in newborn pigs that were subject to seizure with bicuculline (a competitive antagonist of GABA), compared with control pigs and those pretreated with indomethacin. The authors concluded that superoxide reactive species formed by the newborn pig brain during seizures induced by bicuculline and cyclooxygenase metabolism of arachidonic acid may be generating this radical (55). Other reports have demonstrated the relevance of oxidative stress in different experimental models (55-62)and patients (60-68) with epilepsy. Currently, there is particular attention paid to clarifying the role and relevance of oxidative stress in epilepsy, particularly in severe cases, such as SE or other epileptic states.

In the early 2000s, oxidative stress was studied in the epileptic state. The evidence suggested that oxidative stress was important in this neurological pathology. In particular, SE induced by lithium-pilocarpine, pilocarpine, kainic acid, pilocarpine and sleep deprivation or cocaine in animal models (mouse and chick) causes an increase in reactive oxygen species, nitrite levels and lipid peroxidation production. It can also cause a reduction in antioxidant activity of certain enzymes such as nitric oxide synthases (NOS), catalase (CAT), SOD, glutathione peroxidase and glutathione reductase, in addition to reduced glutathione (GSH) levels in the hippocampus, striatum, thalamus, cortex or the whole brain. On the other hand, pretreatment with rosiglitazone (peroxisome proliferator-activated receptor $\gamma$ agonist), tempol (SOD mimetic), muscimol (GABA agonist), FK506 (immunosuppressive agent) or buspirone (partial agonist of the 5-HT1A receptor) diminished the oxidative status while stimulating the antioxidant system (69-81). The complete information is available upon request.

Different antioxidants for the treatment of SE. Although the use of antioxidants as a therapy against epilepsy has been described since 1970s, extensive studies on the use of antioxidants for treatment of SE have been reported since 2000. Different studies have demonstrated the use of antioxidants in $\mathrm{SE}$, for the treatment of $\mathrm{SE}$, indicating that pretreatment with vitamin $\mathrm{E}$, vitamin $\mathrm{C}$, coenzyme Q10, N-acetyl-cysteine, 7-nitroindazole, melatonin and various plant extracts or flavonoids reduces lipid oxidation and restores the activities of SOD, CAT and NOS and the levels of GSH in the rat hippocampus, striatum or cortex (82-100). The complete information is available upon request.

\section{Physiological and therapeutic relevance}

These results will increase the understanding of the close connection between oxidative stress and epileptic state, and provide direct evidence of this association in the experimental models of epilepsy.

Oxidative stress in the epileptic state is a potential condition that requires recognition and management in clinical studies. Therefore, further studies dissecting physiological processes are required in order to establish the most effective and beneficial actions for clinical practice. The comprehension of these processes may lead to novel therapies and treatments that prevent or reduce brain injuries. Furthermore, anti-epileptic drugs are beneficial to the regulation, prevention or inhibition of seizures, although it has been demonstrated that long-term use increases oxidative stress in experimental models and in humans (101). The present study suggests that the use of antioxidants with conventional therapies may provide a beneficial treatment for SE, by diminishing brain oxidative stress induced by these seizures. However, further evidence is required to validate this hypothesis.

\section{Acknowledgements}

The funding was obtained from the National Institute of Pediatrics (Mexico City, Mexico; protocols 034/2013, $014 / 2012,04 / 2013$ and 016/2014). The authors would like to thank Ms. Sergio Humberto Larios-Godínez for the technical assistance.

\section{References}

1. Fisher RS: Redefining epilepsy. Curr Opin Neurol 28: 130-135, 2015.

2. Engel J Jr: Concepts of epilepsy. Epilepsia 36 (Suppl 1): S23-S29, 1995.

3. Engel J Jr and Starkman S: Overview of seizures. Emerg Med Clin North Am 12: 895-923, 1994.

4. Engel JJ and Pedley AT (eds): Introduction to the epilepsies. In: Epilepsy, A Comprehensive Textbook. 1st edition. Lippincott-Raven, Philadelphia, PA, pp765-772, 1997.

5. International League Against Epilepsy: Commission Report 1997. The Epidemiology of the Epilepsies: Future Directions. Epilepsia 38: 614-618, 1997.

6. International League Against Epilepsy (ILAE): Guidelines for epidemiologic studies on epilepsy. Commission on epidemiology and prognosis, ILAE. Epilepsia 34: 592-596, 1993.

7. Hauser WA, Annegers JF and Kurland LT: Incidence of epilepsy and unprovoked seizures in Rochester, Minnesota: 1935-1984. Epilepsia 34: 453-468, 1993.

8. Dichter MA: Emerging insights into mechanisms of epilepsy: Implications for new antiepileptic drug development. Epilepsia 35 (Suppl 4): S51-S57, 1994.

9. Téllez-Zenteno JF and Hernández-Ronquillo L: A review of the epidemiology of temporal lobe epilepsy. Epilepsy Res Treat 2012: 630853, 2012. 
10. Newton CR and Garcia HH: Epilepsy in poor regions of the world. Lancet 380: 1193-1201, 2012.

11. Neligan A, Hauser WA and Sander JW: The epidemiology of the epilepsies. Handb Clin Neurol 107: 113-133, 2012.

12. Annegers JF, Grabow JD, Groover RV, Laws ER Jr, Elveback LR and Kurland LT: Seizures after head trauma: A population study. Neurology 30: 683-689, 1980.

13. International League Against Epilepsy (ILAE): Proposal for revised clinical and electroencephalographic classification of epileptic seizures. Commission on classification and terminology of the ILAE. Epilepsia 22: 489-501, 1981.

14. International League Against Epilepsy (ILAE): Proposal for revised classification of epilepsies and epileptic syndromes. Commission on classification and terminology of the ILAE. Epilepsia 30: 389-399, 1989.

15. Berg AT and Cross JH: Classification of epilepsies and seizures: Historical perspective and future directions. Handb Clin Neurol 107: 99-111, 2012.

16. Cavanna AE, Rickards $\mathrm{H}$ and Ali F: What makes a simple partial seizure complex? Epilepsy Behav 22: 651-658, 2011

17. Fisher RS and Frost JJ: Epilepsy. J Nucl Med 32: 651-659, 1991.

18. Trinka E, Höfler J and Zerbs A: Causes of status epilepticus. Epilepsia 53 (Suppl 4): S127-S138, 2012.

19. Trinka E, Cock H, Hesdorffer D, Rossetti AO, Scheffer IE, Shinnar S, Shorvon S and Lowenstein DH: A definition and classification of status epilepticus - report of the ILAE task force on classification of status epilepticus. Epilepsia 56 $1515-1523,2015$

20. Lowenstein DH, Bleck T and Macdonald RL: It's time to revise the definition of status epilepticus. Epilepsia 40: 120-122, 1999

21. Towne AR, Pellock JM, Ko D and DeLorenzo RJ: Determinants of mortality in status epilepticus. Epilepsia 35: 27-34, 1994.

22. DeLorenzo RJ, Hauser WA, Towne AR, Boggs JG, Pellock JM, Penberthy L, Garnett L, Fortner CA and Ko D: A prospective, population-based epidemiologic study of status epilepticus in Richmond, Virginia. Neurology 46: 1029-1035, 1996.

23. Wu YW, Shek DW, Garcia PA, Zhao S and Johnston SC: Incidence and mortality of generalized convulsive status epilepticus in California. Neurology 58: 1070-1076, 2002.

24. Rossetti AO, Hurwitz S, Logroscino G and Bromfield EB: Prognosis of status epilepticus: Role of aetiology, age, and consciousness impairment at presentation. J Neurol Neurosurg Psychiatry 77: 611-615, 2006.

25. Fountain NB: Status epilepticus: Risk factors and complications. Epilepsia 41 (Suppl 2): S23-S30, 2000.

26. Martín E and Pozo M: Animal models for the development of new neuropharmacological therapeutics in the status epilepticus. Curr Neuropharmacol 4: 33-40, 2006.

27. Nair PP, Kalita J and Misra UK: Status epilepticus: Why, what, and how. J Postgrad Med 57: 242-252, 2011

28. Lothman EW, Bertram EH III and Stringer JL: Functional anatomy of hippocampal seizures. Prog Neurobiol 37: 1-82, 1991.

29. Naylor DE, Liu H and Wasterlain CG: Trafficking of GABA(A) receptors, loss of inhibition, and a mechanism for pharmacoresistance in status epilepticus. J Neurosci 25: 7724-7733, 2005.

30. Carlson H, Ronne-Engström E, Ungerstedt U and Hillered L: Seizure related elevations of extracellular amino acids in human focal epilepsy. Neurosci Lett 140: 30-32, 1992.

31. During MJ and Spencer DD: Extracellular hippocampal glutamate and spontaneous seizure in the conscious human brain. Lancet 341: 1607-1610, 1993.

32. Haglid KG, Wang S, Qiner Y and Hamberger A: Excitotoxicity. Experimental correlates to human epilepsy. Mol Neurobiol 9: 259-263, 1994

33. Cavalheiro EA, Leite JP, Bortolotto ZA, Turski WA, Ikonomidou $\mathrm{C}$ and Turski L: Long-term effects of pilocarpine in rats: Structural damage of the brain triggers kindling and spontaneous recurrent seizures. Epilepsia 32: 778-782, 1991.

34. Ben-Ari Y: Limbic seizure and brain damage produced by kainic acid: Mechanisms and relevance to human temporal lobe epilepsy. Neuroscience 14: 375-403, 1985

35. Sloviter RS and Damiano BP: Sustained electrical stimulation of the perforant path duplicates kainate-induced electrophysiological effects and hippocampal damage in rats. Neurosci Lett 24: 279-284, 1981

36. Lothman EW, Bertram EH, Kapur J and Stringer JL: Recurrent spontaneous hippocampal seizures in the rat as a chronic sequela to limbic status epilepticus. Epilepsy Res 6: 110-118, 1990.
37. Schmidt-Kastner R, Humpel C, Wetmore C and Olson L: Cellular hybridization for BDNF, trkB, and NGF mRNAs and BDNF-immunoreactivity in rat forebrain after pilocarpineinduced status epilepticus. Exp Brain Res 107: 331-347, 1996.

38. Holtzman DM and Lowenstein DH: Selective inhibition of axón outgrowth by antibodies to NGF in a model of temporal lobe epilepsy. J Neurosci 15: 7062-7070, 1995.

39. Reddy DS and Kuruba R: Experimental models of status epilepticus and neuronal injury for evaluation of therapeutic interventions. Int J Mol Sci 14: 18284-18318, 2013.

40. Leite JP, Garcia-Cairasco N and Cavalheiro EA: New insights from the use of pilocarpine and kainate models. Epilepsy Res 50: 93-103, 2002

41. Sloviter RS: Feedforward and feedback inhibition of hippocampal principal cell activity evoked by perforant path stimulation: GABA-mediated mechanisms that regulate excitability in vivo. Hippocampus 1: 31-40, 1991.

42. Lothman EW, Bertram EH, Bekenstein JW and Perlin JB Self-sustaining limbic status epilepticus induced by 'continuous' hippocampal stimulation: Electrographic and behavioral characteristics. Epilepsy Res 3: 107-119, 1989.

43. Hauser WA: The prevalence and incidence of convulsive disorders in children. Epilepsia 35 (Suppl 2): S1-S6, 1994

44. Coppola A and Moshé SL: Why is the developing brain more susceptible to status epilepticus? Epilepsia 50 (Suppl 12) S25-S26, 2009.

45. Rajasekaran K, Zanelli SA and Goodkin HP: Lessons from the laboratory: The pathophysiology, and consequences of status epilepticus. Semin Pediatr Neurol 17: 136-143, 2010.

46. Thompson $\mathrm{K}$ and Wasterlain C: Lithium-pilocarpine status epilepticus in the immature rabbit. Brain Res Dev Brain Res 100: 1-4, 1997.

47. Thompson K, Holm AM, Schousboe A, Popper P, Micevych P and Wasterlain C: Hippocampal stimulation produces neuronal death in the immature brain. Neuroscience 82: 337-348, 1998.

48. Sankar R, Shin DH, Liu H, Mazarati A, Pereira de Vasconcelos A and Wasterlain CG: Patterns of status epilepticus-induced neuronal injury during development and long-term consequences. J Neurosci 18: 8382-8393, 1998

49. Kubová H, Druga R, Lukasiuk K, SuchomelováL, Haugvicová R, Jirmanová I and Pitkänen A: Status epilepticus causes necrotic damage in the mediodorsal nucleus of the thalamus in immature rats. J Neurosci 21: 3593-3599, 2001.

50. Silva AV, Regondi MC, Cipelletti B, Frassoni C, Cavalheiro EA and Spreafico R: Neocortical and hippocampal changes after multiple pilocarpine-induced status epilepticus in rats. Epilepsia 46: 636-642, 2005 .

51. Nairismägi J, Pitkänen A, Kettunen MI, Kauppinen RA and Kubova H: Status epilepticus in 12-day-old rats leads to temporal lobe neurodegeneration and volume reduction: A histologic and MRI study. Epilepsia 47: 479-488, 2006.

52. Mareš P, Kubová H, Hen N, Yagen B and Bialer M: Derivatives of valproic acid are active against pentetrazol-induced seizures in immature rats. Epilepsy Res 106: 64-73, 2013.

53. Choi BH: Oxygen, antioxidants and brain dysfunction. Yonsei Med J 34: 1-10, 1993

54. Bondy SC: The relation of oxidative stress and hyperexcitation to neurological disease. Proc Soc Exp Biol Med 208: 337-345, 1995.

55. Armstead WM, Mirro R, Leffler CW and Busija DW: Cerebral superoxide anion generation during seizures in newborn pigs. J Cereb Blood Flow Metab 9: 175-179, 1989.

56. Dalton T, Pazdernik TL, Wagner J, Samson F and Andrews GK Temporalspatial patterns of expression of metallothionein-I and -III and other stress related genes in rat brain after kainic acid-induced seizures. Neurochem Int 27: 59-71, 1995.

57. Dal-Pizzol F, Klamt F, Vianna MM, Schröder N, Quevedo J, Benfato MS, Moreira JC and Walz R: Lipid peroxidation in hippocampus early and late after status epilepticus induced by pilocarpine or kainic acid in Wistar rats. Neurosci Lett 291: $179-182,2000$

58. Folbergrová J: Oxidative stress in immature brain following experimentally-induced seizures. Physiol Res 62 (Suppl 1): S39-S48, 2013.

59. Cárdenas-Rodríguez N, González-Trujano ME, Aguirre-Hernández E, Ruíz-García M, Sampieri A III, Coballase-Urrutia E and Carmona-Aparicio L: Anticonvulsant and antioxidant effects of Tilia americana var. mexicana and flavonoids constituents in the pentylenetetrazole-induced seizures. Oxid Med Cell Longev 2014: 329172, 2014. 
60. Cárdenas-Rodríguez N, Coballase-Urrutia E, Pérez-Cruz C Montesinos-Correa H, Rivera-Espinosa L, Sampieri A III and Carmona-Aparicio L: Relevance of the glutathione system in temporal lobe epilepsy: Evidence in human and experimental models. Oxid Med Cell Longev 2014: 759293, 2014.

61. Cárdenas-Rodríguez N, Coballase-Urrutia E, Rivera-Espinosa L, Romero-Toledo A, Sampieri A III, Ortega-Cuellar D, Montesinos-Correa H, Floriano-Sánchez E and Carmona-Aparicio L: Modulation of antioxidant enzymatic activities by certain antiepileptic drugs (valproic acid, oxcarbazepine and topiramate): Evidence in humans and experimental models. Oxid Med Cell Longev 2013: 598493, 2013.

62. Carmona-Aparicio L, Pérez-Cruz C, Zavala-Tecuapetla C, Granados-Rojas L, Rivera-Espinosa L, Montesinos-Correa H, Hernández-Damián J, Pedraza-Chaverri J, Sampieri A III, Coballase-Urrutia E and Cárdenas-Rodríguez N: Overview of Nrf2 as therapeutic target in epilepsy. Int J Mol Sci 16: 18348-18367, 2015.

63. Mahle C and Dasgupta A: Decreased total antioxidant capacity and elevated lipid hydroperoxide concentrations in sera of epileptic patients receiving phenytoin. Life Sci 61: 437-443, 1997.

64. Liu CS, Wu HM, Kao SH and Wei YH: Phenytoin-mediated oxidative stress in serum of female epileptics: A possible pathogenesis in the fetal hydantoin syndrome. Hum Exp Toxicol 16 $177-181,1997$.

65. Ono H, Sakamoto A and Sakura N: Plasma total glutathione concentrations in epileptic patients taking anticonvulsants. Clin Chim Acta 298: 135-143, 2000.

66. Sudha K, Rao AV and Rao A: Oxidative stress and antioxidants in epilepsy. Clin Chim Acta 303: 19-24, 2001

67. Mueller SG, Trabesinger AH, Boesiger P and Wieser HG: Brain glutathione levels in patients with epilepsy measured by in vivo (1)H-MRS. Neurology 57: 1422-1427, 2001.

68. Abuhandan M, Calik M, Taskin A, Yetkin I, Selek S and Iscan A: The oxidative and antioxidative status of simple febrile seizure patients. J Pak Med Assoc 63: 594-597, 2013.

69. Yu X, Shao XG, Sun H, Li YN, Yang J, Deng YC and Huang YG: Activation of cerebral peroxisome proliferator-activated receptors gamma exerts neuroprotection by inhibiting oxidative stress following pilocarpine-induced status epilepticus. Brain Res 1200: 146-158, 2008

70. Tsai CY, Chan JY, Hsu KS, Chang AY and Chan SH: Brain-derived neurotrophic factor ameliorates brain stem cardiovascular dysregulation during experimental temporal lobe status epilepticus. PLoS One 7: e33527, 2012.

71. Milatovic D, Zivin M, Gupta RC and Dettbarn WD: Alterations in cytochrome c oxidase activity and energy metabolites in response to kainic acid-induced status epilepticus. Brain Res 912: 67-78, 2001.

72. Costa DA, de Oliveira GA, Lima TC, dos Santos PS, de Sousa DP and de Freitas RM: Anticonvulsant and antioxidant effects of cyano-carvone and its action on acetylcholinesterase activity in mice hippocampus. Cell Mol Neurobiol 32: 633-640, 2012.

73. Tejada S, Roca C, Sureda A, Rial RV, Gamundí A and Esteban S: Antioxidant response analysis in the brain after pilocarpine treatments. Brain Res Bull 69: 587-592, 2006.

74. Tejada S, Sureda A, Roca C, Gamundí A and Esteban S Antioxidant response and oxidative damage in brain cortex after high dose of pilocarpine. Brain Res Bull 71: 372-375, 2007.

75. Dong Y, Wang S, Zhang T, Zhao X, Liu X, Cao L and Chi Z: Ascorbic acid ameliorates seizures and brain damage in rats through inhibiting autophagy. Brain Res 1535: 115-123, 2013.

76. Hirotsu C, Matos G, Tufik S and Andersen ML: Changes in gene expression in the frontal cortex of rats with pilocarpine-induced status epilepticus after sleep deprivation. Epilepsy Behav 27: 378-384, 2013

77. Macêdo DS, de Vasconcelos SM, dos Santos RS, Aguiar LM, Lima VT, Viana GS and de Sousa FC: Cocaine alters catalase activity in prefrontal cortex and striatum of mice. Neurosci Lett 387: 53-56, 2005

78. Tawfik MK: Coenzyme Q10 enhances the anticonvulsant effect of phenytoin in pilocarpine-induced seizures in rats and ameliorates phenytoin-induced cognitive impairment and oxidative stress. Epilepsy Behav 22: 671-677, 2011.

79. Du P, Tang HY, Li X, Lin HJ, Peng WF, Ma Y, Fan W and Wang X: Anticonvulsive and antioxidant effects of curcumin on pilocarpine-induced seizures in rats. Chin Med J (Engl) 125: 1975-1979, 2012.
80. Freitas RM, Vasconcelos SM, Souza FC, Viana GS and Fonteles MM: Oxidative stress in the hippocampus after pilocarpine-induced status epilepticus in Wistar rats. FEBS J 272: 1307-1312, 2005.

81. Freitas RM: Investigation of oxidative stress involvement in hippocampus in epilepsy model induced by pilocarpine. Neurosci Lett 462: 225-229, 2009.

82. Liu ZW, Zhang T and Yang Z: Involvement of nitric oxide in spatial memory deficits in status epilepticus rats. Neurochem Res 32: 1875-1883, 2007

83. Ahmad M: Protective effects of curcumin against lithium-pilocarpine induced status epilepticus, cognitive dysfunction and oxidative stress in young rats. Saudi J Biol Sci 20: 155-162, 2013.

84. Santos LF, Freitas RL, Xavier SM, Saldanha GB and Freitas RM Neuroprotective actions of vitamin $C$ related to decreased lipid peroxidation and increased catalase activity in adult rats after pilocarpine-induced seizures. Pharmacol Biochem Behav 89: $1-5,2008$.

85. Júnior HV, de França Fonteles MM and Mendes de Freitas R Acute seizure activity promotes lipid peroxidation, increased nitrite levels and adaptive pathways against oxidative stress in the frontal cortex and striatum. Oxid Med Cell Longev 2 130-137, 2009

86. Liu J, Wang A, Li L, Huang Y, Xue P and Hao A: Oxidative stress mediates hippocampal neuron death in rats after lithium-pilocarpine-induced status epilepticus. Seizure 19: $165-172,2010$

87. de Freitas RL, Santos IM, de Souza GF, Tomé Ada R, Saldanha GB and de Freitas RM: Oxidative stress in rat hippocampus caused by pilocarpine-induced seizures is reversed by buspirone. Brain Res Bull 81: 505-509, 2010.

88. Peternel S, Pilipović K and Zupan G: Seizure susceptibility and the brain regional sensitivity to oxidative stress in male and female rats in the lithium-pilocarpine model of temporal lobe epilepsy. Prog Neuropsychopharmacol Biol Psychiatry 33: 456-462, 2009

89. Atanasova M, Petkova Z, Pechlivanova D, Dragomirova P, Blazhev A and Tchekalarova J: Strain-dependent effects of long-term treatment with melatonin on kainic acid-induced status epilepticus, oxidative stress and the expression of heat shock proteins. Pharmacol Biochem Behav 111: 44-50, 2013.

90. Tsai HL, Chang CN and Chang SJ: The effects of pilocarpine-induced status epilepticus on oxidative stress/damage in developing animals. Brain Dev 32: 25-31, 2010.

91. Smilin Bell Aseervatham G, Sivasudha T, Suganya M, Rameshkumar A and Jeyadevi R: Trichosanthes tricuspidata modulates oxidative toxicity in brain hippocampus against pilocarpine induced status epilepticus in mice. Neurochem Res 38: 1715-1725, 2013.

92. Nomura S, Shimakawa S, Miyamoto R, Fukui M and Tamai H: 3-Methyl-1-phenyl-2-pyrazolin-5-one or N-acetylcysteine prevents hippocampal mossy fiber sprouting and rectifies subsequent convulsive susceptibility in a rat model of kainic acid-induced seizure ceased by pentobarbital. Brain Res 1590 65-74, 2014.

93. Zeng LH, Zhang HD, Xu CJ, Bian YJ, Xu XJ, Xie QM and Zhang RH: Neuroprotective effects of flavonoids extracted from licorice on kainate-induced seizure in mice through their antioxidant properties. Zhe Jiang Da Xue Xue Bao 14 1004-1012, 2013 (In Chinese)

94. Golechha M, Chaudhry U, Bhatia J, Saluja D and Arya DS: Naringin protects against kainic acid-induced status epilepticus in rats: Evidence for an antioxidant, anti-inflammatory and neuroprotective intervention. Biol Pharm Bull 34: 360-365, 2011.

95. Ambrogini P, Minelli A, Galati C, Betti M, Lattanzi D, Ciffolilli S, Piroddi M, Galli F and Cuppini R: Post-seizure $\alpha$-tocopherol treatment decreases neuroinflammation and neuronal degeneration induced by status epilepticus in rat hippocampus. Mol Neurobiol 50: 246-256, 2014.

96. Xavier SM, Barbosa CO, Barros DO, Silva RF, Oliveira AA and Freitas RM: Vitamin C antioxidant effects in hippocampus of adult Wistar rats after seizures and status epilepticus induced by pilocarpine. Neurosci Lett 420: 76-79, 2007.

97. Barros DO, Xavier SM, Barbosa CO, Silva RF, Freitas RL, Maia FD, Oliveira AA, Freitas RM and Takahashi RN: Effects of the vitamin $\mathrm{E}$ in catalase activities in hippocampus after status epilepticus induced by pilocarpine in Wistar rats. Neurosci Lett 416: 227-230, 2007. 
98. Huang HL, Lin CC, Jeng KC, Yao PW, Chuang LT, Kuo SL and Hou CW: Fresh green tea and gallic acid ameliorate oxidative stress in kainic acid-induced status epilepticus. J Agric Food Chem 60: 2328-2336, 2012.

99. Golechha M, Bhatia J, Ojha S and Arya DS: Hydroalcoholic extract of Emblica officinalis protects against kainic acid-induced status epilepticus in rats: Evidence for an antioxidant, anti-inflammatory, and neuroprotective intervention. Pharm Biol 49: 1128-1136, 2011.
100. Wang SJ, Zhao XH, Chen W, Bo N, Wang XJ, Chi ZF and Wu W: Sirtuin 1 activation enhances the PGC- $1 \alpha /$ mitochondrial antioxidant system pathway in status epilepticus. Mol Med Rep 11: 521-526, 2015.

101. Puttachary S, Sharma S, Stark S and Thippeswamy T: Seizureinduced oxidative stress in temporal lobe epilepsy. Biomed Res Int 2015: 745613, 2015. 